\title{
REALISING THE VISION OF INTEGRATED REPORTING: A CRITICAL VIEWPOINT
}

\author{
Pieter Conradie* \\ University of Pretoria
}

Received: April 2016

\author{
Derick de Jongh" \\ University of Pretoria
}

Accepted: October 2016

\begin{abstract}
The purpose of this paper is firstly to determine whether the International Integrated Reporting (IR) Framework is sufficiently robust to act as the guide for the IR movement. The secondary purpose is to speculate on the constraints that IR will face on its journey towards achieving the aims and vision of the IIRC (International Integrated Reporting Council). The paper is written in the form of a critical viewpoint, and will engage with the relevant academic literature and industry-led initiatives to achieve its objectives. The main finding of this paper is that the potential of the International $\langle\mid R\rangle$ Framework towards achieving its objectives lies more with the way it is applied than the way it was written. Academic literature does however highlight a number of potential constraints that will have to be overcome if integrated reporting is to achieve its long-term vision of financial stability and sustainability.
\end{abstract}

\section{Keywords}

Integrated reporting, assurance, suitable criteria, integrated reporting process, completeness, relevance, sustainability

* Mr P Conradie is a lecturer in the Department of Auditing at the University of Pretoria, South Africa. [pieter.conradie@up.ac.za]

\#Prof $\mathbf{D}$ de Jongh is professor in the Department of Business Management at the University of Pretoria, South Africa. 


\section{INTRODUCTION}

Since the inception in 2009 of the International Integrated Reporting Committee (now Council) (IIRC), the integrated reporting (IR) movement has created a great deal of interest among a wide variety of stakeholders (Cheng et al., 2015). Owing to the ambitious ideals of the IIRC, many actors view IR as the future of corporate reporting, which may address many of the concerns with current corporate reporting (0'Dwyer et al., 2014; IIRC, 2011).

The IIRC's ambitious long-term vision is that the "cycle of integrated thinking and reporting will be a driving force towards global financial stability and sustainability" (IIRC, 2014b:4). Important milestones towards achieving this long-term vision would be to consistently achieve the aims of IR over the short and medium term. The aims of IR are, firstly, to provide information to providers of financial capital in order to facilitate more effective and productive financial capital allocation. The second aim is to "promote a more efficient and cohesive" form of corporate reporting globally. The third aim is to promote "accountability and stewardship" to the broad base of capitals as identified by the IIRC, and lastly to support the type of thinking that focuses on value creation over the short, medium and longer term (IIRC, 2014b:4).

To address the current concerns with financial instability, integrated thinking and reporting would have to have the following impact:

"[L]ower volatility in markets would emerge due to the improved internal decision making and behaviours encouraged by $I R$, as well as the longer term perspective it provided" (0’Dwyer et al., 2014:13).

The proposed positive impact on sustainability would be achieved through:

"... stewardship and accountability for the broad base of capitals [...] and promote understanding of their interdependencies" (IIRC, 2014b:5).

The aim of "stewardship and accountability" is linked to the other aims of IR, namely better corporate reporting and the focus on value creation. This focus on value creation (with a broader view on value) may also identify different forms of value to be unlocked and may assist organisations to identify previously unforeseen risk. A more efficient and productive allocation of capital may identify new and promising sustainable investments (such as impact investments), and may in this way contribute towards sustainability (Eccles and Saltzman, 2011). This paper argues that the aim of "stewardship and accountability" is the main driver of sustainability, with the other aims of IR seen as secondary drivers.

The sustainability reporting literature abounds in warnings about the complexity of what reporting for "true" sustainability would actually entail. Certain scholars (Gray, 2006) are of the opinion that reporting on "true" sustainability in terms of the definition according to the Brundtland Report may not even be possible, and that organisations will only be able to report on how unsustainable they are. Gray believes that, given the understanding that sustainability is a planetary (or global) concept, it cannot be disaggregated to the level of a single organisation. In terms of this view, organisations cannot be seen to improve their sustainability performance, but can only claim to become less unsustainable.

The current thinking on necessary requirements of a move towards sustainable business and society would include: 
- The recognition of a broad accountability to all stakeholders impacting on and affected by the actions of an organisation (Gray and Bebbington, 2007)

- Recognition of, and active engagement with areas of conflict between the potentially competing interests of different stakeholder groups (Gray, 2012)

Given the current limited understanding of the constituent parts of the path to sustainability, a broader accountability towards stakeholders and active engagement in potential conflict will be seen as the issues that integrated reporting will have to address to be a "driving force" towards sustainability.

Alongside the oft-publicised momentum and growth of the integrated reporting movement, less publicised concerns and warnings are also emerging. These concerns will be discussed in more detail later in this paper.

For IR, and the greater IR movement to achieve its ambitious vision, it will have to successfully create an inflection point in both the prevailing short-term strategies of business and unsustainable practices of business. Moreover, to be successful, IR will have to be built on a solid foundation. These observations culminate into the overarching research problem of this study: If the design of the International $\langle\mid R\rangle$ Framework $(\langle\mid R\rangle F W)$ does not support the overall aims and vision for integrated reporting, application of this framework will result in largely meaningless information.

The purpose of this paper is thus to firstly consider whether the $\langle\mid R\rangle$ FW was constructed as a robust enough guide to act as the foundation of the IR movement. The second purpose of the paper is to clarify a number of interrelated concepts in the $\langle\mathrm{IR}\rangle \mathrm{FW}$ that are at risk of being misinterpreted. This way forward will have to address potential concerns about $\langle\mid R\rangle F W$ as a robust guide, as well as the challenges that have been documented in academic literature regarding, among other things, increasing short-termism and the complexities involved in addressing sustainability.

To achieve these aims, the paper will consist of three interrelated areas. Area 1 will consider the suitability of the $\langle\mid R\rangle$ FW as a sufficiently robust guide to fulfill the IIRC vision. Area 2 will identify specific areas within the $\langle R\rangle F W$ that need careful consideration before the way forward is contemplated. Area 3, which also acts as the conclusion to this paper, will consider to what extent relevant recent criticism of IR by academics impacts on the long-term vision of the IIRC in the context of the findings identified in Area $l$ and 2 of this paper.

Area $l$ of this paper will rely on a number of assurance initiatives to achieve its purpose of determining whether the $\langle\mathrm{IR}\rangle \mathrm{FW}$ is a suitable guide to fulfill the IIRC vision. An assurance lens is a relevant instrument for use in this investigation because an assurance provider has to determine whether a reporting framework contains the necessary criteria to act as reporting guidance before an assurance engagement is undertaken. In this way, the assurance provider's stamp of approval on the $\langle\mathrm{R}\rangle \mathrm{FW}$ would not only act as positive affirmation that an integrated report prepared in terms of the $\langle\mid R\rangle F W$ is assurable, but also that the $\langle\mid R\rangle F W$ contains the necessary criteria to act as guidance when preparing an integrated report.

The paper takes the form of a critical viewpoint, and makes use of a combination of academic research and empirical evidence obtained through the feedback process in the $\langle\mathrm{R}\rangle \mathrm{FW}$ development process. The sample of feedback chosen was based on a judgmental sample of the most substantive feedback by recognised international bodies that are deemed to be influential in the international accounting fraternity. 
Given the fact that this paper is written as a critical viewpoint, the findings of this paper are based on critical argumentation, and not verifiable empirical evidence. Samples selected in this paper were largely based on the researcher's judgment, and it was not intended to be representative of the full population. This can also be brought forward as the main limitation of this paper, but given the early stage of IR development, it is believed that the arguments brought forward in this paper add value to the emerging discourse on integrated reporting.

This study contributes to the emerging body of research on integrated reporting in a unique way because it uses an assurance lens to consider the technical robustness of the $\langle\mathrm{R}\rangle \mathrm{FW}$. It therefore advances the research into the assurance of integrated reports, as well as providing practical insights into the way that the $\langle I R\rangle$ FW should be applied to achieve the aims of the IIRC.

\section{DETERMINING THE SUITABILITY OF THE <IR〉 FW AS A GUIDE}

\subsection{Introductory remarks: $\langle I R>F W$ as a guide to the IR movement}

To explore the suitability of the $\langle\mathrm{R}\rangle \mathrm{FW}$ to act as a guide, this paper will consider whether it was designed in such a way as to deliver the information needed to achieve the IIRC aims and future vision. To achieve this, it should have the ability to render information that is relevant, complete, reliable, understandable and unbiased (IIRC, 2013c:9). The aforementioned characteristics of useful information are also, incidentally, the characteristics of suitable criteria as discussed in the International Framework for Assurance Engagements (IFAE).

Even though the characteristics of suitable criteria are primarily a concept considered by assurance providers, they are deemed to be equally relevant to reporters. Reporters of information (in this case integrated reports) need to ensure that the characteristics of criteria that they use in the preparation of the information ensure that this information can be assured (IIRC, 2013c), as well as being useful to the intended audience. The criteria of relevance and completeness will be the main focus point of this paper, because these criteria have proved to be particularly difficult to assure in a sustainability reporting context (0'Dwyer and Owen, 2007; 0 'Dwyer et al., 2011; Manetti, 2011), and it is the contention of this paper that these characteristics will continue to be a challenge in the IR context.

The starting point of this investigation will be to consider an effort by the International Auditing and Assurance Standards Board (IAASB) to assess whether its Global Reporting Initiative (GRI) G3 Guidelines exhibited suitable criteria for the purposes of the assurance of a sustainability report (Simnett and Nugent, 2006). This paper argues that there are important similarities between the sustainability reporting process and the integrated reporting process, particularly in aspects relating to relevance and completeness. For this reason the lessons learnt through the IAASB process may shed light on the investigations in this paper.

The public comment period during 2013 solicited responses on whether respondents believed that the IR Consultation Draft (the precursor to the $\langle\mathrm{IR}\rangle \mathrm{FW}$ ) contained suitable criteria to achieve its aims. The paper will therefore consider a number of the responses received to the IIRC's call, as well as the way in which the IIRC responded to these responses and the impact they had on the $\langle\mathrm{R}\rangle \mathrm{FW}$.

Finally, the first area will also consider the latest publications (on the assurance of integrated reports) of the IIRC, in which it explored issues around whether the framework contained the characteristics of suitable criteria, or more specifically whether the $\langle\mathrm{R}\rangle \mathrm{FW}$ can be viewed as a 
robust guide to achieve its aims, and ultimately its long-term vision. These publications requested public comment, and these comments will be considered and discussed.

\subsection{The 2006 IAASB initiative to determine whether the GRI G3 Guidelines constituted suitable criteria for an assurance engagement}

A literature search was performed to determine whether any academic research had been performed to evaluate whether a conceptual or a reporting framework exhibited the characteristics of suitable criteria in accordance with the International Framework for Assurance Engagements (IFAE). An academic paper with direct relevance to this purpose was published by Wallage (2000). In his paper, Wallage considers "examples and characteristics of criteria that are needed to evaluate management assertions regarding sustainability" (Wallage, 2000:53). The views of Wallage (2000) are considered throughout this paper.

It is important to note that a number of academic publications exist that consider the challenges that the assurance provider may face when assuring the completeness and relevance of sustainability reports (0'Dwyer, 2005; 0'Dwyer, 2011; Manetti, 2011). It should, however, be noted that these investigations focused specifically on the completeness and relevance of information reported by organisations, not the completeness and relevance of the reporting framework or guidelines used to prepare the reports in the first instance. This is an important distinction to make because the consideration of a reporting framework (in its totality) as relevant and complete raises a different set of questions from those considering the relevance and completeness of disclosures in an integrated report or a sustainability report.

In the absence of academic literature to guide this paper's area of inquiry, it was therefore decided (as a matter of necessity rather than convenience) to consult industry-led initiatives to ascertain the characteristics of suitable criteria for a reporting framework (or reporting guidelines). Apart from the work that was undertaken by the IIRC during 2013 and 2014, which will be dealt with in the next section, it was found, as mentioned above, that the IAASB undertook a process in 2006 that is of interest to this investigation.

Even though this initiative was primarily concerned with the GRI G3 guidelines, the approach followed and the feedback received were deemed to be relevant for the purposes of the current investigation. The reason for this relevance is the fact that the $G 3$ guidelines recommend a materiality-determination process that has commonalities with that of the $\langle\mathrm{R}\rangle \mathrm{FW}$, and it is suggested here that the lessons learnt in this process could be of use when considering the results of the IIRC initiatives.

In the 2006 Consultation Paper the IAASB invited "individual accountants, accounting firms and IFAC member bodies" to review the G3 Reporting Guidelines and provide feedback to the GRI by a certain date.

One of the aims of the 2006 Consultation Paper was to:

"encourage professional accountants to consider whether $\mathrm{G} 3$ would be acceptable as

"suitable criteria" for an assurance engagement" (Simnett and Nugent, 2006:2).

The authors of the 2006 Consultation prepared a set of questions for each of the criteria with the intention of stimulating the thinking of respondents. Since this paper will focus primarily on the criteria of relevance and completeness, the more specific questions posed in relation to relevance and completeness are repeated below: 
In terms of relevance:

"Does the multi-stakeholder process employed by GRI in developing the Guidelines ensure that they are relevant (to the decision making by the intended users)? Are there any situations where the Guidelines would not be relevant?" (Simnett and Nugent, 2006:10)

In terms of completeness

"The more supplementation that is needed, the more likely it is that $\mathrm{G} 3$ would not gain universal acceptance as being sufficiently complete" (Simnett and Nugent, 2006:10).

Despite the apparent lack of transparency around the IAASB feedback process, we were advised "off the record" that a total of six responses were received to the IAASB Consultation Paper. The respondents were among the most prominent international professional accounting bodies.

In response to the questions regarding relevance and completeness, the following responses shed light on some of the potential challenges: (these are among the responses that were received "off the record")

The process of developing criteria must involve stakeholder dialogue.

Stakeholder dialogue is a condition for assessing reporting completeness and relevance.

The assurance provider will have to assess the adequacy of the stakeholder engagement process.

None of the responses received expressed a conclusive opinion on the suitability of $\mathrm{G} 3$ as criteria for an assurance engagement. Nor did the IAASB publish any follow-up to the 2006 consultation paper. We therefore argue that the poor response rate and lack of substantive responses could have been among the reasons for the lack of IAASB follow-up.

The paper by Wallage (2000:64) brings an added perspective to the observations by the respondents. Wallage contends that due to the forward-looking nature of certain sustainability disclosures, the assurance of systems and processes may be more relevant than the assurance of "retrospective behavior and data". Both the respondents to the IAASB and Wallage (2000) stress the importance of assessing stakeholder dialogue in the process of expressing an opinion on relevance and completeness. More specifically, Wallage's view is that the assurance provider should understand and investigate the stakeholder dialogue process through which the reporting organisation determined its reporting criteria. He states that this dialogue process plays an inherent part in determining whether the suitability, relevance and completeness criteria have been satisfied.

A perspective raised by Wallage (2000:58), which was not specifically raised by the respondents to the IAASB paper, is that the assessment of the suitability of criteria should be "similar to the verification objectives to be met by the assurance provider". This implies that the assurance providers should obtain sufficient and appropriate audit evidence of the selection of reporting criteria by the reporter being investigated.

There is once again a subtle difference between the consideration of whether the report being assured is relevant and complete, and the question of whether the criteria that were used to prepare the report were relevant and complete, and the role that stakeholder dialogue played in this process. 
In an ideal environment, the development of the criteria should include stakeholder dialogue, to ensure that the criteria that will be used to prepare the report are relevant and complete (pre report). This process will normally involve a stakeholder engagement process to determine the needs, interests and expectations of stakeholders (IIRC, 2013d).

\subsection{Concluding remarks on the IAASB Consultation Paper}

The poor response to the IAASB Consultation Paper is to be regretted because it appears that the constituents did not deem it worth their time to comment on whether the G3 Guidelines were designed in such a way so as to achieve the aims set out. This poor response to the question on suitable criteria was also reflected in the feedback received on the 2013 IR Consultation Draft (specifically regarding the question posed on suitable criteria) - most probably due to the fact that it was perceived as a question that was relevant only to assurance providers. This is however a misconception (Hoang and Simnett, 2013), because the suitability of the GRI or the $\langle\mathrm{R}\rangle \mathrm{FW}$ as a guideline should be of fundamental concern to all stakeholders, because it is a question of whether it is an instrument fit for its purpose.

The most likely explanation for the poor response rate is simply that the Consultation Paper did simply not pique the interest of constituents, and a response to this paper was simply not deemed to be worthy of the effort. The only logical reasons for this lack of interest could possibly be:

- Apathy towards or ignorance of respondents of the actual importance of having suitable criteria (Gray et al., 2014)

- The fact that the reasons for engaging in sustainability reporting may be disconnected from the purposes envisaged by the GRI

The real reason why this initiative by the IAASB was not successful will remain a matter of speculation. Nevertheless, the responses that were received to the IAASB Consultation Paper are useful to this paper because they point to the importance of stakeholder involvement in ensuring that the completeness and relevance criteria have been met.

A final note of particular interest in this context is the fact that the commentary cited in this section was made by professional accounting bodies. The inclusion of stakeholders in the establishment of criteria can be viewed as a progressive step towards greater accountability. The fact that accountants voiced these views potentially points toward a realisation on the part of accountants that greater accountability is needed to improve the quality of sustainability reporting.

\subsection{Reflections on the IIRC due process and Consultation Draft commentary period}

As part of the framework development process of the IIRC, a Consultation Draft of the Framework was launched during April 2013. The purpose of the consultation draft was to solicit feedback from all interested stakeholders on the suitability of the principles and content elements contained in the consultation draft, with the intention of incorporating these responses in the $\langle\mid R\rangle F W$, which was scheduled for release during December 2013 (IIRC, 2013b).

Like the Consultation Paper by the IAASB (Simnett and Nugent, 2006), the IR Consultation Draft (CD) contained a number of questions soliciting responses by interested parties on a number of 
areas of the framework. The most relevant of the questions for the purposes of this paper was Question 20, which read as follows:

"Please provide any other comments you have about Credibility (Section $5 \varepsilon$ ). Assurance providers are particularly asked to comment on whether they consider the Framework provides suitable criteria for an assurance engagement." (IIRC, 2013b:3)

A sample of prevalent accounting bodies was analysed to gain insight into the prevailing thinking on the $\langle\mid R\rangle$ FW as suitable criteria. This sample was based on a study performed by the Albert Luthuli Centre for Responsible Leadership in 2013 (Conradie et al., 2013). In this study, all the respondents to the 2013 Consultation Draft were allocated to specific cohorts (groups with similar attributes), and a representative sample was selected from each of these cohorts. The sample used for this paper is based on the sample used for the study by Conradie et al. (2013). To create a certain level of consistency and comparability, the same organisations were used for the analysis of the assurance papers (Iater on in Area 1) as those used for the analysis of the Consultation Draft feedback.

As is evident from TABLE 1 , the majority of comments from investors, other organisations, specific agenda organisations and companies are categorised under the "no comment' section. This denotes that these organisations did either not understand the question, or did not have any substantive opinion regarding the matter at hand. Given the fact that suitable criteria are normally considered only by assurance providers in non-financial assurance engagements, it follows logically that meaningful responses would be forthcoming from accounting bodies. For this paper it would therefore also make sense to analyse these comments to gain insight into the way the experts perceive the matter.

The comments that follow are deemed to represent some of the most common themes. The responses below address the suitability of criteria in a collective way, and unfortunately do not specifically isolate the relevance and completeness issues discussed earlier in this paper. They do however highlight important considerations that are indirectly relevant to gaining insight into relevance and completeness.

Even though the Integrated Reporting Committee of South Africa (IRC of SA) (2013) did not take a definitive position on whether the Consultation Draft was suitable, it did comment on the fact that a determining factor on whether the resultant $\langle\mid R\rangle$ FW would be deemed suitable would be "the actual process followed during exposure and the responsible and transparent consideration of comments received before the Framework is finalized" (IRC of SA, 2013).

The Institute for German Auditors (IDW) (2013) commented that it did not believe that the CD represented suitable criteria because it did not "require adequate systems, processes or internal controls as a basis for management assertions" (IDW, 2013).

The American Institute for Certified Public Accountants (AICPA) (2013) took the definitive position that the $C D$ did not constitute suitable criteria; however, it believed that the proposed supplementation with other frameworks might render the $\langle\mid R\rangle$ FW suitable. This implied that areas in which the $\langle\mid R\rangle$ FW might be lacking (e.g. measurement) might be supplemented by other relevant frameworks, and that this combination between the $\langle\mathrm{R}\rangle \mathrm{FW}$ and other reporting frameworks would satisfy the requirements of suitable criteria (AICPA, 2013). 


\begin{tabular}{|c|c|c|c|c|c|c|}
\hline & & & & $\langle\mid R\rangle$ & Wis: & \\
\hline & $\begin{array}{l}\text { Total } \\
\text { responses }\end{array}$ & $\begin{array}{l}\text { responses } \\
\text { for } \\
\text { question } \\
20\end{array}$ & $\begin{array}{c}\text { No } \\
\text { comment }\end{array}$ & $\begin{array}{l}\text { Not } \\
\text { suitable } \\
\text { criteria }\end{array}$ & $\begin{array}{l}\text { Suitable } \\
\text { criteria }\end{array}$ & $\begin{array}{c}\text { Other } \\
\text { comment }\end{array}$ \\
\hline $\begin{array}{l}\text { Accounting } \\
\text { Institutes }\end{array}$ & 31 & 9 & 1 & 5 & 2 & 1 \\
\hline Big Four Firms & 6 & 4 & 1 & 2 & & 1 \\
\hline $\begin{array}{l}\text { Corporate } \\
\text { Governance } \\
\text { institutions }\end{array}$ & 14 & 3 & 1 & & & 1 \\
\hline Companies & 88 & 13 & 8 & 1 & & 4 \\
\hline Consultants & 48 & 7 & 4 & 1 & 1 & 1 \\
\hline Investors & 52 & 8 & 7 & & & 1 \\
\hline $\begin{array}{c}\text { Other } \\
\text { organisations }\end{array}$ & 43 & 6 & 5 & & & 1 \\
\hline $\begin{array}{c}\text { Specific } \\
\text { agenda } \\
\text { organisations }\end{array}$ & 56 & 8 & 6 & 1 & & \\
\hline $\begin{array}{l}\text { Standards } \\
\text { setters }\end{array}$ & 21 & 6 & 2 & 3 & & 1 \\
\hline $\begin{array}{l}\text { Accounting } \\
\text { Institutes }\end{array}$ & 31 & 9 & 1 & 5 & 2 & 1 \\
\hline Total & 359 & 64 & 35 & 13 & 3 & 11 \\
\hline
\end{tabular}

Source: Adapted from Conradie et al. (2013)

The Institute of Chartered Accountants for England and Wales (ICAEW) (2013) stated that it was too early to express an opinion on whether the CD constituted suitable criteria, as it would need more experimentation before conclusions could be drawn.

Both the International Federation of Accountants (IFAC) (2013) and the Dutch Organisation for Professional Accountants (NBA) (2013) concurred that the IAASB needed to be involved in the framework development process to ensure the assurability of the $\langle I R>F W(I F A C, 2013)$ (NBA, 2013).

Hoang and Simnett (2013) performed a high-level analysis of the responses to question 20, and found that a total of 62 respondents (out of a possible 359) provided their comments to this question, and only 13 of these felt that the $\langle\mid R\rangle$ FW provided suitable criteria for an assurance engagement (Hoang and Simnett, 2013).

According to the question 20 feedback (Hoang and Simnett, 2013), the uncertainty as to whether the $\langle\mid R\rangle$ FW provides suitable criteria for both preparation and assurance of an integrated report is self-evident. 
The problem that this creates is twofold:

1. Without suitable criteria, no level of comfort can be reached on whether the information in the integrated report is relevant and complete.

2. Assurance of the integrated report will not be possible without suitable criteria.

The question 19 in the Consultation draft read as follows:

"If assurance is to be obtained, should it cover the integrated report as a whole, or specific aspects of the report? Why?" (IIRC, 2013b)

Analysis of the feedback to Question 19 revealed that $80.3 \%$ of respondents believed that assurance in some form should be provided over the integrated report (Hoang and Simnett, 2013). The credibility of integrated reports will therefore be highly problematic without assurance.

Upon closer scrutiny, the comments of the IRC of SA (2013), the NBA (2013) and IFAC (2013) all effectively point to the importance of following due process to ensure the assurability of the $\langle R\rangle$ $\mathrm{FW}$, even though the reasons for pointing it out differed (IRC of SA - transparency and due process considerations; NBA and IFAC - IAASB involvement). It is, however, important to note that the recommendation that the IAASB should be involved in the framework development process points to an important legitimising role that the IAASB could play in the framework development process.

A consideration of the due process as followed by the International Accounting Standards Board (IASB) appears to support the important role that the IAASB plays in International Financial Reporting Standards (IFRS) development (IFRS Foundation, 2013). The IASB engages with a range of stakeholders during the development of new accounting standards, but for the purposes of this discussion, the most important stakeholder with whom they engage is the International Audit and Assurance Standards Board (IAASB). The IAASB is requested to comment on the assurability of the proposed accounting standard, and the IASB will not issue new accounting standards before the assurability of the standard has been demonstrated (IFRS Foundation, 2013).

This points to an important difference between the due process followed by the IIRC and the one followed by the IASB to develop reporting standards. It would be highly unlikely that the IASB would consider issuing accounting standards before the assurability thereof had been illustrated. It would thus appear to be an issue of concern that there was very little outcry when the IIRC issued its reporting FW before assurability thereof could be demonstrated. Admittedly, in this scenario we compare the development of a framework (in the $\langle I R\rangle$ FW case) to that of standards (in IFRS case), and it might be argued that more variables may be at play in the case of the development of a framework versus a standard.

The consideration of due process is an important part when considering the suitability of criteria when an assurance engagement is performed in terms of the International Standard on Assurance Engagements (ISAE) 3000 (revised) (IFAC, 2013b). ISAE 3000 (revised) states that the assurance provider would not have to consider the suitability of criteria if the criteria themselves were developed through a transparent due process by a recognised body of experts. It is therefore interesting to note that the uncertainties around the $\langle\mathrm{R}\rangle$ FW still persist even though it can be argued that a robust due process was followed in its development. It might be beyond the scope of this paper, but by considering the involvement of the IAASB in IFRS standard development, a lot can be said about what constitutes a valid due process. It might be argued that the $\langle\mathrm{R}\rangle$ FW due process is to be questioned because it did not involve the IAASB, hence severely undermining its validity due to questions of assurability. 
This consideration of the importance of due process implies that IR assurance will be performed within the current paradigm of assurance of other types of information. There is, however, no certainty as to how the assurance on IR may develop over time. The feasibility of other approaches to assurance may become more appropriate as IR evolves. (Refer to IIRC (2014a) for a discussion of other possible approaches to the assurance of integrated reports.)

\subsection{IIRC reaction to concerns raised by Consultation Draft respondents}

As part of the IIRC's commitment to transparency in its $\langle I R>F W$ developments process (IIRC, 2012), it published its responses to the concerns raised by respondents in its Basis for conclusions document (IIRC, 2013a)

The IIRC acknowledged concerns raised by respondents regarding the suitability of the proposed $\langle I R\rangle F W$ as criteria. The IIRC was also of the opinion that the suitability of the $\langle\mid R\rangle F W$ as criteria was as much a concern to preparers of integrated reports as it was to the assurors thereof (IIRC, $2013 a$ ). The formal response of the IIRC was to include an additional content element into the $\langle\mid R\rangle$ FW that requested preparers of reports to disclose "significant frameworks and methods used to quantify or evaluate material matters" (IIRC, 2013a).

It is, however, evident from the analysis of this paper that the concerns raised by the IDW (2013), IFAC (2013), ICAEW (2013) and the NBA (2013) were specifically addressed in neither the Basis for conclusions nor the $\langle\mathrm{R}\rangle \mathrm{FW}$.

The IIRC developed a number of papers on assurance that was also followed by a feedback process. These papers and the feedback thereon shed further light onto the question of whether the $\langle\mid R\rangle$ FW constitutes suitable criteria.

The IIRC made a number of comments indicating that it did not see itself as an assurance standards setter (IIRC, 2014a), but it nevertheless embarked on a process of developing two reports to stimulate the debate on the assurance of integrated reports. These two reports, released during July 2014, were entitled Assurance on IR: an introduction to the discussion (IIRC, 2014b) and Assurance on IR: an exploration of issues (IIRC, 2014a).

These two documents and the feedback received on them are discussed in the following section.

\subsection{The assurance papers}

The Introduction to the discussion paper is effectively a short introduction to the issues that are discussed in the Exploration of issues paper (IIRC, 2014b; IIRC, 2014a). For the purposes of this discussion, we will focus more on the Exploration paper: it is, however, relevant to note the section in the Introduction paper that discussed the importance of investment-grade information. The two most relevant paragraphs are included below:

"For information to be 'investment grade', it must be credible and trusted by the providers of financial capital. Information provided by an organization without any assurance is unlikely to achieve this level of credibility and trust" (IIRC, 2014b:6)

and

"If this benefit (of enhancing trust and credibility) is not realized, and integrated reports are not considered to be 'investment grade', the aims of $\langle\mid R\rangle$ are not likely to be realized." (IIRC, 2014b:6) 
It is evident from these statements that the IIRC acknowledges the importance of obtaining assurance on integrated reports, and that it is seen as a crucial part of the sustained legitimacy of integrated reporting. The IIRC also states that the providers of financial capital are not likely to view the information in the integrated report as "investment grade" without an appropriate level of assurance (IIRC, 2014b:6).

The Introduction document (IIRC, 2014b) also contains a number of questions that solicit feedback from respondents regarding certain aspects of the ongoing integrated reportingassurance debate.

In the Exploration of issues document the IIRC explores a number of issues that it deems important to be considered in the debate on the assurance of integrated reports. Most important for our purposes is the section that considers the suitability of the framework as criteria. In line with the rest of the paper, this discussion will now focus on relevance, completeness and the overall conclusion as per the Exploration document (IIRC, 2014a).

The IIRC expresses little concern about whether the criterion of relevance has been met, because in its estimation all the content elements within the $\langle\mid R\rangle$ FW are directed towards providing information to the providers of financial capital.

It is, however, more circumspect when it considers whether the completeness criterion has been met. In response to the question on the completeness criterion, the IIRC poses a return question:

"What requirements should have been included in the Framework that were not?"

(IIRC, 2014a:25)

It further notes that the greatest barrier to assure completeness at this point would be the high levels of judgment that would required of the assurance provider. This is, however, deemed to be a short-term concern until best practice emerges.

In the section concluding whether the $\langle\mid \mathrm{R}\rangle \mathrm{FW}$ in its totality constitutes suitable criteria (based on the discussion of all the individual criteria), the IIRC contends that there are two schools of thought on this:

The first group believes that the $\langle\mathrm{R}\rangle \mathrm{FW}$ contains suitable criteria, given the amendments that were made (inclusion of basis of preparation and presentation paragraph in the $\langle\mathrm{R}\rangle \mathrm{FW}$ ).

The second group believes that the $\langle\mid R\rangle$ FW may be suitable if it is combined with the disclosure of the measurement policies that have been utilised by the reporter. In essence, this group believes that the only shortcoming of the $\langle\mathrm{R}\rangle \mathrm{FW}$ is that it does not contain principles or prescriptions as to the type of measurement frameworks or methods. It does not elaborate on any further fundamental shortcomings, and it believes that integrated reports will still be assurable as long as assurance providers conclude on the relevance of the measurement policies on a case-by-case basis. This view does not imply that assurance will focus solely on measurement. It means that suitable criteria can be reached for the assurance engagement in totality if appropriate measurement instruments are developed or adopted. It does not necessarily point towards the strategy that the assurance provider should follow during the assurance process.

The IIRC concludes that the current phase of integrated reporting should be viewed as a journey, and that the current variability in integrated reports should not be a barrier to viewing the framework as suitable. It compares the evolution of other reporting frameworks (like accounting) to the $\langle\mid R\rangle$ FW, and argues that the variability of these other frameworks has not been a barrier to their being viewed as suitable. 
An important final point of discussion that will be relevant for this analysis is contained in Par 4.52 of the Exploration paper. This paragraph states that the $\langle\mathrm{R}\rangle \mathrm{FW}$ is not aimed at providing guidance on process matters, even though some guidance is provided on the materiality determination process. The onus of suitable criteria for processes would rest on report preparers, and these can be developed internally or adopted from other reporting frameworks (IIRC, 2014a:26).

\subsection{Feedback: the Assurance papers}

A total of 61 responses (IIRC, 2014c) were received to the call for comment on the Assurance on $\langle/ R\rangle-$ Introduction paper. As mentioned earlier in this paper, the researcher has used for this analysis the same sample of organisations that were used for Consultation Draft feedback analysis, for the purpose of identifying major trends.

An interesting trend in this round of feedback was that the IFAC (2014) and the AICPA (2014) chose not to address any of the questions that were posed in the Assurance paper, but rather to comment on the processes that they put in place to monitor the trends in IR assurance. The IFAC did, however, point to the fact that the IAASB had established a working group to develop a discussion paper on integrated reporting. The fact that these bodies decided not to respond to any of the questions in the Assurance paper may be a possible indication that they chose to "err on the side of caution", and wait for IR practice to evolve further before making any further statements in this regard.

More substantive comments were received from the Det Norske Veritas Germanischer Lloyd (DNV GL) Round Table (Roundtable, 2014) and ICAS (2014). These comments pointed towards the importance of addressing the challenges of assuring the IR early in the IR development process, to ensure the assurability of IR content.

The role of robust systems of control and reporting processes in the generation of evidence to support the materiality and completeness assertions by management were raised by a number of respondents (Adams, 2014; IDW, 2014; FEE, 2014). The comments of Carol Adams (2014:2) captured this concern most succinctly as follows:

"The credibility of IR is more dependent on the processes than the accuracy of the numbers."

Arguably the most important trend identified was concern about the question of whether the debate around assurance was market-led or driven by the accounting profession and regulators (FEE, 2014; ICAEW, 2014). This concern is echoed in a different shape by the IDW (2014), by asking the question of whether the providers valued integrated reporting enough to require assurance to ensure credibility and trust. The DNV GL (2014) Roundtable added an insightful final perspective to this debate. It asked whether it was sufficient to represent the interests of only the providers of financial capital, while the providers of the other five types of capital were not treated with equal importance.

The final comments that will be included in this context are the remarks provided by ICAS (2014). ICAS stressed the fact that a key aspect of being able to do assurance would be to assure that the reporting organisation developed a holistic working definition of value in its report that was in accordance with the "thrust" of the $\langle I R\rangle$ FW. According to ICAS, this definition would be necessary to ensure that all material increases and decreases of the different types of capitals were adequately disclosed in the integrated report. 
The discussion of the $\langle\mathrm{IR}\rangle \mathrm{FW}$ as suitable criteria brought a number of perspectives to the surface. The most important of these are:

- It is important to consider the assurability of the $\langle\mathrm{R}\rangle \mathrm{FW}$ early in the evolution of the IR movement.

- The $\langle\mid R\rangle F W$ is vague in a number of areas and allows for the subjective interpretation of its concepts.

- The $\langle\mid R\rangle$ FW offers limited guidance on the processes that will ultimately support the generation of an integrated report.

- The transparent due process followed by the IIRC in the $\langle\mathrm{R}\rangle \mathrm{FW}$ development process adds positive momentum to the argument for its possibly representing suitable criteria.

- The $\langle\mid R\rangle$ FW does not have any intention to prescribe measurement methods, and reporters would have to develop these internally or use other existing frameworks or standards for this purpose.

It is beyond the scope of this paper to provide conclusive evidence on whether the $\langle\mathrm{R}\rangle \mathrm{FW}$ constitutes suitable criteria for the preparation of an integrated report. There are, however, a number of perspectives that may shed light on this debate.

The first perspective relates to a hypothetical scenario relating to the Conceptual Framework of the International Accounting Standards Board. Should a reporter be in the (unfortunate) position of having to prepare a set of financial statements without the use of the International Financial Reporting Standards (IFRS), this reporter would have to make use of the Conceptual Framework to assist him/her with this task.

In the scenario described above, the reporter would have to develop accounting treatments for all the elements of financial statements internally. Should an assurance provider then wish to audit the aforementioned financial statements, this auditor would have to consider each of the individual accounting treatments individually and come to a conclusion on whether these treatments were in some way within the spirit or thrust of the Conceptual Framework.

It follows that the specific accounting treatments developed by the reporter would be the reporting criteria that the auditor would have to consider, with the Conceptual Framework as an overall guide.

The current debate going on as to whether the $\langle\mid R\rangle$ FW exhibits the characteristics of suitable criteria can now be considered in the light of the above scenario. In this scenario the right question to ask would not necessarily be whether the $\langle\mathrm{R}\rangle \mathrm{FW}$ represents suitable criteria, but rather whether the $\langle\mathrm{R}\rangle \mathrm{FW}$ contains the necessary guidance to enable a reporter to develop the necessary criteria to facilitate the IR process, and then ultimately the preparation of an integrated report itself.

By following this line of reasoning it becomes possible to answer the question that the IIRC posited to readers of the Assurance on $\langle/ R\rangle$ : an exploration of issues document:

\subsection{What requirements should have been included in the Framework that were not?}

Based on the findings in Area 1 of this paper, the answer to this question would have to be that the $\langle\mathrm{IR}\rangle \mathrm{FW}$ : 
1. is not necessarily intended to represent suitable criteria in itself, but rather provide guidance towards developing criteria in the individual circumstances of a reporter (in the same way that the IASB Conceptual Framework is intended to facilitate the development of IFRS that will ultimately be the reporting criteria).

2. may need to provide more specific guidance on required processes and systems that will enable the ultimate preparation of an integrated report. These processes are not specifically related to the year-end processes to prepare an integrated report, but rather the processes that are crucial to defining value, and the impact of this definition of value on the materiality determination process (Refer to Area 2 of this paper).

\section{SPECIFIC AREAS WITHIN THE 〈IR> FW THAT WARRANTS SPECIFIC CONSIDERATION}

\subsection{Clarification of $\langle I R\rangle$ FW concepts}

As discussed in the introduction of this paper, it is important to clarify a number of interrelated concepts in the $\langle\mid R\rangle$ FW that are at risk of being misinterpreted. It will become apparent in this discussion that the potential of $I R$ to become a driving force for change does not necessarily reside with how the $\langle\mid R\rangle$ FW has been written, but rather with how an organisation chooses to interpret and implement it.

This clarification builds on the findings of Area $l$ of the paper, because it highlights a number of areas that were not explicitly addressed during the $\langle\mathrm{R}\rangle \mathrm{FW}$ development process. We argue that the areas that will be discussed in this part of the paper could have had a substantive impact on the $\langle\mid R\rangle$ FW development process if they had been given the necessary due consideration. These areas are:

- The potentially ambiguous interpretation of materiality

- The importance of defining value

\subsection{Unpacking the potentially ambiguous interpretation of materiality determination: Process vs. Report}

In traditional accounting theory, the concept of materiality is used as a measure during the auditing process to determine a threshold of when misstatements may affect the decisionmaking of intended users. This understanding will also be relevant when an assurance engagement on integrated reports is undertaken. This interpretation of materiality is, however, not within the scope of this paper.

The specific meaning that the concept of materiality assumes in an integrated reporting context relates more to the aspect of recognition of relevant issues in an integrated report. It follows that in terms of the current understanding of the $\langle\mathrm{IR}\rangle \mathrm{FW}$, a matter would be recognised in the integrated report if it affected, or had the ability to affect, the ability of the relevant organisations to create value and be deemed relevant to the primary intended report users.

The definition of materiality was, however, adjusted between the Consultation Draft and the $\langle\mid R\rangle$ FW. The relevant section in the Consultation Draft read that a matter was material if it could affect the decision-making by the primary intended users, while in the $\langle\mathbb{R}\rangle \mathrm{FW}$ it read that a matter would 
be deemed material if it could affect an organisation's ability to create value. According to the IIRC in the summary of significant issues, "value creation has been linked to the organization itself, rather than to the audience" (IIRC, 2013c:26).

This amendment points to a very important distinction that has not been discussed by the IIRC, or in academic literature since the release of the $\langle\mathrm{R}\rangle \mathrm{FW}$ in December 2013. The new definition of materiality implies that any matter that may affect value creation should be deemed material by the reporting organisation (process materiality), but that it should report this matter only if the reporting organisation deems it to be relevant to the primary intended report user (reporting materiality). This implies that matters that are deemed material to overall value creation may not necessarily be material to (influence the decision-making of) the primary intended report users. If the earlier claims by the IIRC that the information needs of long-term investors are aligned with those of broader society hold true, the aforementioned process materiality and reporting materiality should be similar. This assumption by the IIRC is, however, not supported by empirical evidence, and current academic thinking appears to contradict this assumption (0’Dwyer et al., 2014).

\subsection{The importance of defining value}

The potential existence of two different sets of material matters will, however, be largely dependent on the way that an organisation defines value. It follows logically that a process of defining value should precede the materiality determination process. The materiality determination process will then use this internally developed definition of value as its guiding principle to perform its materiality assessments. The $\langle\mathrm{R}\rangle \mathrm{FW}$ does not specifically define the concept of value and is silent on the importance of arriving at this definition before embarking on the process of determining materiality.

The way that value is defined in an IR context is discussed in some detail by Flower (2014). According to Flower, focusing the definition of value towards the providers of financial capital essentially precludes other possible interpretations of the meaning of value. More specifically, Flower concludes that value to society, stakeholders and the environment is by implication excluded from the integrated report if it does not directly contribute to how an organisation creates value for itself - unless it is for a specifically stated purpose (Flower, 2014).

In the final analysis, Flower concludes that value should be taken to mean "value to investors". It is, however, important to note that Flower's discussion of value does not include the information contained in paragraphs 2.8 and 2.9 of the $\langle\mathrm{R}\rangle$ FW. Paragraph 2.8 discussed the potential of positive and negative externalities to affect an organisation's value-creation ability (IIRC, 2013d). Paragraph 2.9 deals with value creation over different "time horizons". According to par. 2.9 , overall value creation is unlikely to be maximised over the longer term if one form of capital is maximised while others are disregarded. The example used to exemplify this warning is the danger of maximising financial capital at the expense of human capital (IIRC, 2013d:11).

It appears that Paragraph 2.8 and 2.9 may provide a more nuanced and inclusive understanding of value than the meaning held by Flower. Flower's selective discussion has definite merit, but it is not necessarily a deathblow to a broader understanding and interpretation of value. As discussed earlier, the viewpoint held in this paper is that the reporting process is not biased towards a specific stakeholder, while the preparation of the integrated report itself is biased towards the providers of financial capital (which implies a more biased interpretation of value as of interest to investors). 
The implication of this thinking around two types of materiality (process and reporting) and the importance of defining value before determining materiality predicate the importance of a welldeveloped reporting process. In a well-managed organisation, all the matters that affect value creation will have to be considered as part of this process. An appropriate response to addressing these material matters would have to be developed, and it might warrant either a strategic or a mitigating response, or both. As was illustrated earlier, the primary intended users may not necessarily have an interest in all of these responses, but that does not mean that they might not have a direct impact on the operational or strategic management of the reporting entity.

In line with this interpretation of materiality as defined in the $\langle\mathrm{R}\rangle \mathrm{FW}$, the transformative power that IR may have on an organisation will largely be contingent upon its own internally developed definition of value. Should an organisation choose to understand value in its broadest sense (including progressive rights to other forms of capital), the resultant materiality-determination process should source a consistently broad number of material issues to be addressed. If the organisation, however, chooses the traditional narrow definition of value (only focused on financial issues), the resultant materiality-determination process will source a consistently narrow number of issues to address. This will in turn limit the transformative power of IR because it will prevent the organisation from having to consider anything different to what it is used to doing.

Before concluding this line of thinking, it should be noted that this understanding of value and its impact on the materiality-determination process is primarily an issue that will form part of the IR process. The IR process referred to here is not specifically intended to mean the process of compiling the integrated report at the end of the year. This understanding is more fundamental to the way that value is understood and considered in the core of the organisation strategy and risk-management activities. As was discussed earlier in this part of the paper, the report itself will be prepared with the specific interests of the providers of financial capital in mind, and it will only extract information relevant (from the IR process) that will be of interest to the providers of financial capital.

Even though this understanding of value is not made explicit in the $\langle\mid R\rangle F W$, the flexibility in the $\langle\mid R\rangle$ FW allows this interpretation of value and the underlying conceptual difference between the process and the report. The mere fact that the definition of materiality was amended in the final $\langle\mathrm{R}\rangle \mathrm{FW}$ to allow a broader interpretation is evidence of this.

The value and impact that IR might have by focusing on the integrated reporting process appears to be different from the value and impact that it might have through the integrated report alone. The ultimate potential value and impact of integrated reporting therefore does not lie in the way that the framework has been written, but more directly in the way that an organisation chooses to apply it.

The unfortunate reality is that the majority of reporters have not invested in the necessary systems and processes to apply integrated reporting (the process) in its purest sense (IIRC, 2014a). The IIRC's current focus on the Integrated Report itself (IIRC, 2014a) is not aiding the cause of leveraging the transformative impact that IR may potentially effect. 


\section{CONCLUSION}

\subsection{Constraints that IR will face in achieving its long-term vision}

This, the third and final area of this paper, will consider how relevant recent criticism of IR by academics impacts on the long-term vision of the IIRC in the context of the findings identified in Area $l$ and 2 of this paper.

For the purpose of this conclusion, the most relevant findings of Area 1 and 2 are:

1. The $\langle I R\rangle$ FW does not necessarily preclude the achievement of the long-term vision of the IIRC.

2. The way that an individual organisation interprets and implements integrated reporting will be the most important factor that will determine whether the aims and vision of the IIRC are realised.

In view of the findings in Area 1 and 2 of this paper, the ability of IR (and the cycle of integrated thinking) to be a driver towards financial stability and sustainability (the long term vision of the IIRC) is a "testable proposition" rather than a proven fact (0'Dwyer et al., 2014). The current emergent global practice of organisations' implementing IR can be seen as the laboratory wherein an experiment is underway to provide evidence for and against this "testable proposition".

Based on the views developed in this paper, along with insights from relevant academic literature, emergent IR practice may face a number of constraints on the journey towards achieving its aims and vision (0'Dwyer et al., 2014; Gray, 2012; Tweedie, 2014).

The IIRC (and the $\langle\mathrm{R}\rangle \mathrm{FW}$ ) chose as its main focus the integrated report, and not the greater integrated reporting process (IIRC, 2014a). As implied in the conclusion to Area 2 of this paper, this focus diverts the attention away from the potential transformative power of the process towards the report itself. In theory, the report will necessitate supporting processes, but with the focus on the final product and not the process to achieve this product, it is the view of this paper that this is the first and most important constraint on the potential success of IR.

The second constraint lies in the lack of evidence regarding demand from mainstream investors (0'Dwyer et al., 2014). This concern is given further impetus by the supposed lack of evidence of the existence of long-term investors and increasing evidence of short-termism (Milesi-Ferretti and Tille, 2011; 0'Dwyer et al., 2014). A crucial element towards the achievement of the vision of financial stability will be to provide decision-useful information to investors, especially those with a longer investment horizon (0'Dwyer et al., 2014).

The third and final constraint also lies with the predominant position afforded to the providers of financial capital. There is very little evidence that the providers of financial capital will surrender power to the other forms of capital of their own accord (Tweedie, 2014; 0'Dwyer et al., 2014). It appears that IR's focus on the providers of financial capital further embeds this position and detracts from its ability to achieve greater accountability towards other less powerful stakeholders (Tweedie, 2014). To achieve the vision of sustainability, the IR movement would have to find a way to afford greater accountability towards society and the environment. The primary position afforded to the providers of financial capital appears to stand in direct opposition to this. 
At this stage of experimentation with IR, it is unclear how the current focus of integrated reporting practice (on the report and providers of financial capital) will address the concerns raised above (regarding the achievement of the long-term vision of the IIRC), because the IIRC appears to recommend a direction directly opposed to its own proposed vision. In this case, experimentation with IR will cause it to "wither on the vine" (0'Dwyer et al., 2014:29), along with earlier reporting initiatives.

As was stated, the main limitation of this paper lies in the fact that it was written as a critical viewpoint. This limited the scope of samples selected, and the findings were largely based in critical argumentation. The emerging practice of assurance on integrated reports does however create fertile ground for future research.

Based on the findings of this paper, two main avenues of future research become important. The first is to investigate the development of international guidance by the IAASB on integrated reporting assurance, and the factors that influence this discourse. The second lies in empirical work on the way that assurance practice of integrated reports evolves. This work can be based either on the content analysis of integrated reporting assurance statements, or on qualitativebased interviews with assurance providers to gain a sense of their evolving understanding of the assurance of integrated reports.

\section{LIST OF REFERENCES}

Accountability (2011). AA1000 Stakeholder Engagement Standard 2011. Final Exposure Draft.

Adams, C. (2014). Feedback to Assurance Challenges Questions. Melbourne.

AICPA (American Institute of Certified Public Accountants) (2013). Consultation Questions Feedback. AICPA, New York.

AICPA (American Institute of Certified Public Accountants) (2014). Feedback to Assurance Challenges Questions, AICPA, New York.

Cheng, M., Green, W.J. and Ko, J.C.W. (2015). The impact of strategic relevance and assurance of sustainability indicators on investors' decisions. Auditing: A Journal of Practice and Theory, 34(1), pp. 131-162.

Conradie, P., Schorn, A. and Swart, R. (2013). IR Yearbook 2013: Current Realities and Future Considerations. University of Pretoria, Pretoria.

Eccles, R.G. and Saltzman, D. (2011). Achieving sustainability through integrated reporting. Stanford Social Innovation Review, 59, pp. 56-61.

FEદ (Fédération des Experts-comptables Européens) (2014). Feedback to Assurance Challenges questions, FEદ, Brussels.

Flower, J. (2014). The International Integrated Reporting Council: a story of failure. Critical Perspectives on Accounting, doi 10.1016/j.cpa.2014.07.002.

Gray, R.H. (2006). Does sustainability reporting improve corporate behaviour? Wrong question? Right time? Accounting and Business Research, 36, pp. 65-88.

Gray, R.H. (2012). Integrated reporting: Integrated with what ... and for whom? The Loop, 5. 
Gray, R.H. and Bebbington, J. (2007). Corporate sustainability, accountability and the pursuit of the impossible dream, In: Handbook of Sustainable Development, edited by G Atkinson, S. Dietz and G. Neumeyer, Edward Elgar, pp. 376-394.

Gray, R.H., Adams, C. and Owen, D. (2014). Accountability, Social Responsibility and Sustainability: Accounting for Society and the Environment, Pearson Education.

Hoang, H. \& Simnett, R. (2013). Consultation Question Analysis: Questions 19 and 20: Credibility. UNSW, London.

ICAS (Institute of Chartered Accountants of Scotland) (2014). Feedback to Assurance Challenges questions, ICAS, Edinburgh.

IDW (Institut der Wirtschaftsprüfer) (2013). Consultation questions feedback, IDW, Dusseldorf.

IDW (Institut der Wirtschaftsprüfer) (2014). Feedback to Assurance Challenges questions, IDW. Dusseldorf.

IFAC (International Federation of Accountants) (2013). Consultation questions feedback, IFAC, New York.

IFAC (International Federation of Accountants) (2013b). International Standard on Assurance Engagements 3000 (revised), IFAC, New York.

IFAC (International Federation of Accountants) (2014). Feedback to Assurance Challenges questions, IFAC, New York.

IFRS Foundation (2013). IASB and IFRS Interpretations Committee: Due Process Handbook. IFRS Foundation, London.

IIRC (International Integrated Reporting Council) (2011). <Towards integrated reporting: Communicating value in the 21st century Discussion Paper.pdf $>$.

IIRC (International Integrated Reporting Council) (2012). IIRC Due Process. IIRC, London.

IIRC (International Integrated Reporting Council) (2013a). Basis for Conclusions: International $\langle/ R\rangle$ Framework, IIRC, London.

IIRC (International Integrated Reporting Council) (2013b). Consultation Draft of the International $\langle/ R\rangle$ Framework, IIRC, London.

IIRC (International Integrated Reporting Council) (2013c). Summary of Significant Issues: International $</ R>$ Framework, IIRC, London.

IIRC (International Integrated Reporting Council) (2014a). Assurance on $\langle/ R\rangle$ : an Exploration of Issues, IIRC, London.

IIRC (International Integrated Reporting Council) (2014b). Assurance on $\langle/ R\rangle$ : an introduction to the discussion, IIRC, London.

IIRC (International Integrated Reporting Council) (2014c). Submissions in response to the Assurance on $\langle/ R\rangle$ papers, IIRC, London. Available: http://www.theiirc.org/resources-2/assurance/ [Accessed 2015-02-10.]

IIRC (International Integrated Reporting Council) (2013d). The International <IR > Framework, IIRC, London.

IRC OF SA (Integrated Reporting Committee of South Africa) (2013). Consultation questions feedback, IRC of SA, Johannesburg. 
Manetti, G.T. and Toccafondi, S. (2011). The role of stakeholders in sustainability reporting assurance. Journal of Business Ethics, 107, pp. 363-377.

Milesi-Ferretti, G.M. and Tille, C. (2011). The great retrenchment: international capital flows during the global financial crisis. Economic Policy, 26, pp. 289-346.

NBA (Nederlandse Beroepsorganisatie van Accountants) (2013). Consultation Questions feedback. NBA, Amsterdam.

O'Dwyer, B.O. and Owen, D.L. (2005). Assurance statement practice in environmental, social and sustainability reporting: a critical evaluation. The British Accounting Review, 37(2), pp. 205-229.

0 'Dwyer, B.0. and Owen, D. (2007). Seeking stakeholder-centric sustainability assurance: an examination of recent sustainability assurance practice. The Journal of Corporate Citizenship, 25, p. 77.

O’Dwyer, B.0., Owen, D. and Unerman, J. (2011). Seeking legitimacy for new assurance forms: The case of assurance on sustainability reporting. Accounting, Organizations and Society, 36, pp. 31-52.

O'Dwyer, B.0., Humphrey, C. and Unerman, J. (2014). The Rise of Integrated Reporting: Understanding Attempts to Institutionalize a New Reporting Framework. Seminar at the University of Bergamo.

Roundtable, D.G. (2014). Feedback to Assurance Challenges questions, DNV GL Roundtable, San Francisco.

Simnett, R. and Nugent, M. (2006). Assurance aspects of G3: The Global Reporting Initiative's 2006 Draft Sustainability Reporting Guidelines: Consultation Paper. IFAC, New York.

Tweedie, D. (2014). Integrated Reporting: Symptom or Cure of New Capitalism's I/Is? Paper presented at the Conference on New Perspectives on Accounting, Quebec, Canada.

Wallage, P. (2000). Assurance of sustainability reporting: An auditor's view. Journal of Practice and Theory, Supplement, 19, pp. 53-65. 